\title{
Using admission statistics to encourage diverse applicants to MD-PhD programs
}

\author{
Briana Christophers ${ }^{1}$ and Ruth Gotian ${ }^{2,3}$ \\ 'Weill Cornell/Rockefeller/Memorial Sloan Kettering Tri-Institutional MD-PhD Program, New York, New York, USA. ${ }^{2}$ Mentoring Academy and ${ }^{3}$ Department of Anesthesiology, Weill Cornell Medicine, New York, \\ New York, USA.
}

$T_{1}$ here has been consistent interest in bolstering the physician-scientist workforce to fuel discovery and translational research $(1,2)$. In 2014, the PhysicianScientist Workforce Working Group assembled by the NIH identified increasing diversity of the physician-scientist workforce as a priority for the future advancement of the profession; at the time, almost three-quarters of $\mathrm{NIH}$ research project grant recipients with an $\mathrm{MD}-\mathrm{PhD}$ were White, and greater than two-thirds were male $(3,4)$. Even so, women and underrepresented minorities (URMs), which include Black/African Americans, Hispanics/Latinos, and Native Americans/American Indians, remain underrepresented. The enrollment data for 2018-2019 show that women made up $39.9 \%$ of matriculated MD-PhD students, up from $37.7 \%$ in 2014-2015 (5). In the past five years, the rate for women enrolled has increased at about $0.55 \%$ per year. Even if growth continued at the 2018-2019 rate (1.1\%), it would take another ten years for parity to be reached between men and women enrolled in $\mathrm{MD}-\mathrm{PhD}$ programs.

Similar trends emerge for URM MD-PhD students: the graduating class of 2018 had $13.8 \%$ URM graduates, whereas 2018-2019 matriculants included 12.1\% URMs $(6,7)$. For that academic year, $16 \%$ of applicants were URMs (8). These data highlight that there has been almost no growth in the number of URM MD-PhD students matriculating compared with those who matriculated 8-10 years prior (i.e., graduating class of 2018). Additionally, it is necessary to examine reasons why potential women and URM applicants decide not to apply to MD-PhD programs from the outset.

\section{The story admissions statistics} tell

Potential applicants spend considerable time on the internet looking for information about individual MD-PhD programs. A study focused on minority students who applied to medical school revealed that "[t]he few [participants] who searched school websites for information about the admissions process reported that the quality of the websites mattered, being critical resources for students with no other access to information" (9). Although the study population focused on medical students, this suggests that providing accurate and clear data on websites could be a way of raising awareness about programs for women and URM applicants with no other source of reliable information about applying, such as a mentor, family member, or pre-health advisor. URM premedical students cite lack of mentorship and advising as a barrier to applying to medical school, with some receiving information when they felt it was too late, leaving them at a disadvantage (10). Data on premedical women college students show that they are more likely than male undergraduates to view premedical course grades as a barrier to medical school admission (11). Thus, potential applicants look online for details to inform whether or not they should apply in order to maximize their chances relative to the upfront costs of applying.

Applicants have access to the Medical School Admissions Requirements database if they purchase it through the Association of American Medical Colleges (AAMC), which compiles statistics such as grade point average (GPA) and Medical College Admission Test (MCAT) scores that are useful for those creating a list of schools to which to apply. Howev-

Conflict of interest: The authors have declared that no conflict of interest exists.

Copyright: ( 2020, American Society for Clinical Investigation.

Reference information: / Clin Invest. 2020;130(1):17-19. https://doi.org/10.1172/JCI134941.

er, these data are not as useful for those applying to $\mathrm{MD}-\mathrm{PhD}$ programs, who have a slightly different application process. For MD-PhD applicants, quantity and quality of research experience often play into the admissions decision, but this is difficult to compare across applicants, since many (29.7\%) who end up matriculating in programs have at least one year of prior research (12). Therefore, potential applicants may try to use metrics that can be compared among applicants, such as MCAT score or GPA, to guide their application process. Some potential applicants might even turn to anonymous online forums such as Student Doctor Network and Reddit, where they can scroll through posts to gauge their chances of being considered for, and accepted into, an $\mathrm{MD}-\mathrm{PhD}$ program. The self-selection bias of those who post on these sites may paint an unbalanced picture of who is applying, and the advice provided is given by anyone on the internet, whether or not they are familiar with the admissions procedures at different programs. Furthermore, postings represent the perception of just one person using a pseudonym, so their reliability cannot be confirmed.

Some potential applicants may come across statistics published by the AAMC that show the mean, minimum, and maximum GPA and MCAT scores for MD-PhD matriculants. For 2018 matriculants the mean GPA was $3.79 \pm 0.19$ with a range of 2.68-4.00, and the mean MCAT score was $515.6 \pm 5.6$ with a range of 497-528 (13). These data can be both intimidating and comforting. The data are intimidating if one considers the means and standard deviations, which suggest a distribution with a very negative skew, with 50 percent of matriculants earning an MCAT score above the 92nd percentile or having a GPA greater than 3.8. However, the data might be comforting to some because the minimum GPA and MCAT composite score of 
A MCAT score reported
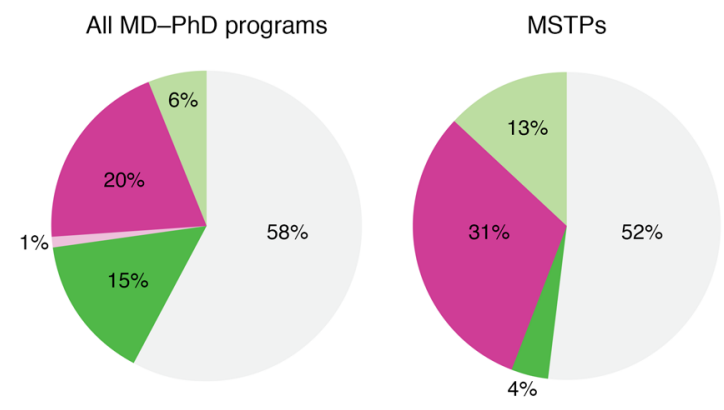

\section{Other MD-PhD programs}

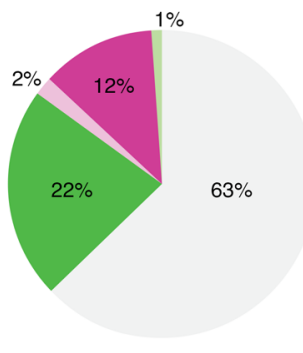

B Grade point average reported
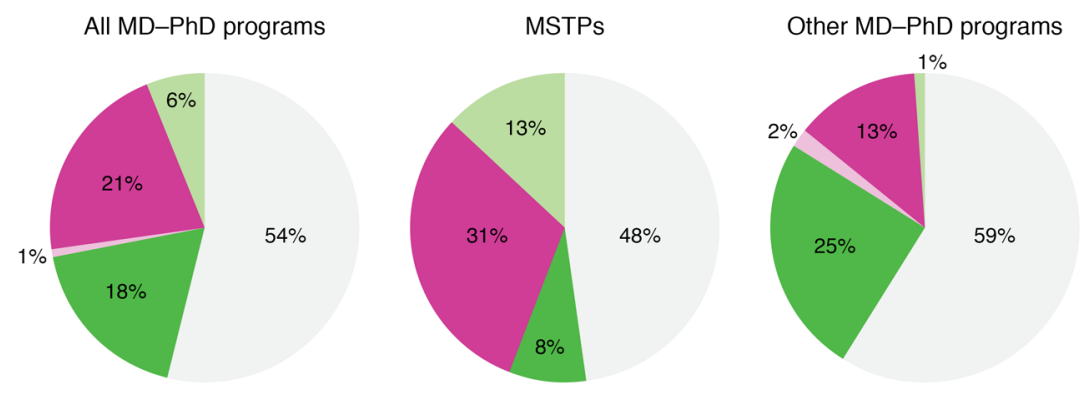

Not reported

Minimum

Median

Mean

Figure 1. Categories of admissions statistics reported by MD-PhD programs on their websites. (A) MCAT exam scores. (B) Grade point averages. Pie charts represent the data for all MD-PhD programs (left), Medical Scientist Training Programs (MSTPs; middle), and other MD-PhD programs (right). The colors represent the categories of admissions statistics (minimum, median, mean, range, and no statistics reported) presented on the websites.

matriculants are 2.75 and 495.0, respectively. It should also be noted that a study of MD-PhD enrollees who took the MCAT in the early 2000 s showed that $92.1 \%$ of applicants had an MCAT score in the upper two quintiles, which may be daunting to those with lower scores (14). The fact that this information can be both intimidating and comforting simply adds to the uncertainty of potential applicants trying to determine whether they are competitive.

The MCAT and GPA data on interviewees, accepted applicants, and matriculants provided by $\mathrm{MD}-\mathrm{PhD}$ programs vary drastically. Searching the internet in late June 2019, we identified that 116 of $121 \mathrm{MD}-\mathrm{PhD}$ programs had a website with specific admissions-related details. More than 50 percent of programs included no information regarding MCAT score or GPA for individuals who applied to, interviewed at, were accepted to, or matriculated into their program (Figure 1). One-fifth of program websites listed a mean MCAT score and GPA; the majority did not include a standard deviation, making the mean difficult to interpret. Less than ten percent of programs included a range for these statistics on their website, although NIH-funded Medical Scientist Training Programs were more likely than other $\mathrm{MD}-\mathrm{PhD}$ programs to include a range (13\% vs. $1 \%$, respectively).

These data points are used by potential applicants as critical information when deciding whether and where to apply. Therefore, these data can serve to encourage more potential applicants to submit applications because they may feel more qualified, or they can be a deterrent, depending on how they are presented. Similarly, information (e.g., means without standard deviations) suggesting that only those with high scores are accepted into a program may contribute to self-selection by women and URM applicants out of the application process due to fear of not being sufficiently qualified. The lack of accurate information may be feeding into imposter syndrome for women and URM applicants and thus acting as a deterrent. Interestingly, women are more likely to apply to lower-ranking MD-PhD programs, again suggesting that some applicants may be applying depending on the programs for which they believe they are qualified (15).

\section{Imposter syndrome}

Students battling impostor syndrome feel they are not smart or talented enough to pursue this profession (16). Furthermore, they live in constant fear that they will be exposed as a fraud and asked to leave their program. This perception is internalized and over time eats away at their self-confidence. The fear, when exacerbated, can result in anxiety, stress, or depression (17). Imposter syndrome is manifested by comparing oneself to others, not feeling academically prepared and on par with peers, and questioning the validity of one's acceptance into a program $(18,19)$.

The literature about the experience of premedical students, especially women and minorities, is currently limited. However, there is evidence for increased attrition of these groups in premedical required courses and STEM majors due to seeing grades and GPA as a marker of competency or fit for the career path $(11,20,21)$. The fear associated with imposter syndrome may cause individuals not to apply if they do not feel they are the perfect applicant with average or above-average MCAT scores and GPA. Lack of knowledge as to the full ranges of these scores does little to alleviate their concerns.

\section{Redefining the ideal MD-PhD candidate}

Having clear and accessible information on successful applicants to individual programs would be a simple step toward improving equity in the MD-PhD application process. Publishing the range of MCAT scores and GPAs of those that a program has accepted, perhaps over a range of time such as ten years, would allow those considering applying to make informed decisions about their candidacy. In this way, women and URM applicants who may have been deterred by lack of information or misleading high-mean statistics for many programs would instead have sufficient information that might make them more likely to apply. Pooling the data for accepted students over a certain period 
of time would ensure that this range would not identify individuals who matriculate at smaller programs or specific individuals in a matriculating class. Above all, this strategy would be a simple step toward redefining the manufactured image of academic perfection (i.e., high GPA and MCAT score with many publications) that many believe represents those who will be successful applicants and future physician-scientists.

\section{Acknowledgments}

BC was supported by a Medical Scientist Training Program grant from the National Institute of General Medical Sciences of the NIH under award number T32GM007739 to the Weill Cornell/ Rockefeller/Memorial Sloan Kettering Tri-Institutional MD-PhD Program.

Address correspondence to: Ruth Gotian, 525 East 68th Street, Box 124, New York, New York 10065, USA. Phone: 212.746. 5412; Email: rgotian@med.cornell.edu.

1. Daye D, Patel CB, Ahn J, Nguyen FT. Challenges and opportunities for reinvigorating the physician-scientist pipeline. JClin Invest. 2015;125(3):883-887.

2. Martin DM, Rathmell WK, Tavazoie SF. Balancing dual demands on the physician-scientist workforce. JClin Invest. 2018;128(8):3204-3205.

3. NIH. Physician Scientist Working Group Report 2014. https://report.nih.gov/workforce/psw/ index.aspx. Updated June 30, 2018. Accessed November 11, 2019.

4. Milewicz DM, Lorenz RG, Dermody TS, Brass
LF, National Association of MD-PhD Programs Executive Committee. Rescuing the physician-scientist workforce: the time for action is now. JClin Invest. 2015;125(10):3742-3747.

5. Association of American Medical Colleges. Table B-11.2: Total MD-PhD Enrollment by U.S. Medical School and Sex, 2014-2015 through 20182019. http://www.aamc.org/download/321554/ data/factstableb11-2.pdf. Updated November 19, 2018. Accessed November 11, 2019.

6. Association of American Medical Colleges. Table B-13: Race/Ethnicity Responses (Alone and In Combination) of MD-PhD Graduates of U.S. Medical Schools, 2013-2014 through 20172018. http://www.aamc.org/download/450638/ data/factstableb13.pdf. Updated November 27, 2018. Accessed November 11, 2019.

7. Association of American Medical Colleges. Table B-9: MD-PhD Matriculants to U.S. Medical Schools by Race/Ethnicity and State of Legal Residence, 2018-2019. http://www.aamc.org/ download/321546/data/factstableb9.pdf. Updated November 13, 2018. Accessed November 11, 2019.

8. Association of American Medical Colleges. Table B-7: MD-PhD Applicants to U.S. Medical Schools by Race/Ethnicity and State of Legal Residence, 2018-2019. http://www.aamc.org/ download/321542/data/factstableb7.pdf. Updated November 13, 2018. Accessed November 11, 2019.

9. Hadinger MA. Underrepresented minorities in medical school admissions: a qualitative study. Teach Learn Med. 2017;29(1):31-41.

10. Freeman BK, Landry A, Trevino R, Grande D, Shea JA. Understanding the leaky pipeline: perceived barriers to pursuing a career in medicine or dentistry among underrepresented-inmedicine undergraduate students. Acad Med. 2016;91(7):987-993.

11. Grace MK. Parting ways: sex-based differences in premedical attrition. Soc Sci Med. 2019;230:222-233.

12. Ahn J, Watt CD, Man LX, Greeley SA, Shea JA.
Educating future leaders of medical research: analysis of student opinions and goals from the MD-PhD SAGE (Students' Attitudes, Goals, and Education) survey. Acad Med. 2007;82(7):633-645.

13. Association of American Medical Colleges. Table B-10: MCAT Scores and GPAs for MD-PhD Applicants and Matriculants to U.S. Medical Schools, 2016-2017 through 2018-2019. http://www.aamc.org/download/321548/data/ factstableb10.pdf. Updated November 27, 2019. Accessed November 11, 2019.

14. Jeffe DB, Andriole DA, Wathington HD, Tai RH. The emerging physician-scientist workforce: demographic, experiential, and attitudinal predictors of MD-PhD program enrollment. Acad Med. 2014;89(10):1398-1407.

15. Bowen CJ, Kersbergen CJ, Tang O, Cox A, Beach MC. Medical school research ranking is associated with gender inequality in MSTP application rates. BMC Med Educ. 2018;18(1):187.

16. Brookfield SD. The Skillful Teacher. 3rd ed. San Francisco, California, USA: Jossey-Bass; 2015.

17. Clance PR, Imes SA. The impostor phenomenon in high achieving women: dynamics and therapeutic intervention. Psychotherapy: Theory, Research and Practice. 1978;15(3):241-247.

18. Sakulku J. The impostor phenomenon. The Journal of Behavioral Science. 2011;6(1):75-97.

19. Hoang $Q$. The impostor phenomenon: overcoming internalized barriers and recognizing achievements. The Vermont Connection 2013;34:42-51.

20. Beasley MA. Why they leave: the impact of stereotype threat on the attrition of women and minorities from science, math and engineering majors. Social Psychology of Education . 2012;15(4):427-448.

21. Witherspoon EB, Vincent-Ruz P, Schunn CD. When making the grade isn't enough: the gendered nature of premed science course attrition. Educational Researcher. 2019;48(4):193-204. 